\title{
Streptococcus dysgalactiae subsp equisimilis
}

National Cancer Institute

\section{Source}

National Cancer Institute. Streptococcus dysgalactiae subsp equisimilis. NCI Thesaurus. Code C86906.

A subspecies of facultatively anaerobic, Gram positive, cocci shaped bacteria in the phylum Firmicutes. This subspecies is positive for Lancefield group G, beta hemolysis, arg inine deamination, esculin hydrolysis, beta glucuronidase, and growth in $6.5 \% \mathrm{NaCl}$ and negative for alpha and beta galactosidase, catalase, and pyrrolidonylarylamidase. It can ferment trehalose, and ribose but not sorbitol, or glycogen. S. dysgalactiae subsp. equisimilis is found in the human respiratory tract and vagina and is pathogenic, causing pharyngitis, impetigo, cellulitis, septicemia, glomerulonephritis, and toxic shock. 